\title{
A atualidade do conceito de gerações na pesquisa sobre o envelhecimento
}

Alda Britto da Motta ${ }^{1}$

Resumo: Se a definição de gerações esteve na preocupação dos estudiosos desde os primórdios da sociologia, por outro lado sua utilização foi sempre teoricamente instável, porque polissêmica e, mesmo quando alcançado um grau de estruturação teórica alta, com Mannheim, também acompanhou a instabilidade inicial da aceitação teórica desse autor em alguns meios acadêmicos. Hoje a polissemia se mantém, mas também uma escassa atenção (ou percepção) às posições sociais geracionais e à dinâmica das relações entre as gerações, ao ponto de causar certos prejuízos analíticos, como no caso aqui apontado da violência contra os idosos - onde a análise do ponto de vista da solidariedade e do conflito entre as gerações é crucial. Palavras-chave: gerações, velhice, gênero, relações intergeracionais, violência.

\section{Introdução}

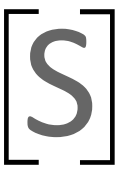

oa meio estranho estar pretendendo expor a atualidade de um conceito que tem sido discutido, e tentativamente atualizado, na sociologia, desde seus primórdios, pelo menos desde Augusto Comte. Ainda não chegamos lá...? Não chegamos, até porque, de vez em quando, esta discussão fica esquecida...

O que corresponde em parte à dificuldade posta pela polissemia do termo, mas também à consideração do próprio percurso acadêmico da obra de Mannheim, relativamente pouco estudado, por períodos esquecido, recente e lentamente reintroduzido - e não apenas no Brasil. Na França, por exemplo, depois de anos de restrições e críticas a Mannheim, O problema das gerações é traduzido apenas em 1990, ganhando uma boa interpretação - "Introdução" e "Posfácio" - de Gérard Mauger. Depois disso, já aí contando com o trabalho sistemático principalmente de Attias-Donfut e de Guillemard, os estudos das gerações desenvolvem-se amplamente naquele país.
1. Professoradoutora da Universidade Federal da Bahia, Programa de Pós-Graduação em Ciências Sociais (PPGCS) e Núcleo de Estudos Interdisciplinares sobre a Mulher (Neim). aldamotta@hotmail.com. 
Curiosamente, no caso do uso do conceito de gerações, mesmo sendo tão iluminador, não se encontram adesões de meio termo a ele. Ou tem-se percebido claramente a sua utilidade ou indispensabilidade analítica como catalisador das relações entre grupos de idade no tempo histórico e na mudança social; ou se tem deixado as conexões sociais coletivas referidas à vivência e experiência no tempo histórico "esquecidas", porque parecem demasiado fluidas ou mutáveis, de um dinamismo exagerado que parece contrariar algumas das "certezas" objetivas da ciência.

Seria, então, de perguntar-se: por que a dificuldade de perceber-se a condição geracional? A posição geracional do sujeito? Ou a dinâmica social do ponto de vista das relações entre as gerações?

Em primeiro lugar, pelo aspecto multifacetado como se realiza e pela referida polissemia do termo. E, em segundo lugar, pela intercambialidade dos termos que a definem e dos lugares sociais a que se referem.

A geração, em um sentido amplo, representa a posição e atuação do indivíduo em seu grupo de idade e/ou de socialização no tempo. Daí o sentido dinâmico ou instável e plural que essa condição, de saída, representa. Mas o que a muitos parece insegurança de meios ou demasiada brevidade de realização e, portanto, aparente inexpressividade existencial, mas também epistemológica - mudança de idade de cada indivíduo a cada ano, assim como a gestação de uma nova geração a cada nova pulsação da vida social em verdade significa o fazer-se estrutural de uma dimensão da vida social, que é, contraditoriamente, tecida com afetividade e relações de poder. Ao mesmo tempo complexamente entretecida com outros sistemas de relações, expressões das dimensões de gênero e classe social. Essa mudança, das idades e gerações, em suas posições e também conflitos no tempo, perturba os estudiosos que se detêm sobre o assunto.

É que historicamente a sociedade, a par de ter-se desenvolvido tendo a idade - e o sexo/gênero - como critérios fundamentais de organização e integração social, principalmente de participação na divisão do trabalho, foi construindo, ao mesmo tempo, formas organizativas outras que redundaram em discriminação, marginalização ou exclusão igualmente baseadas na idade - assim como em critérios relativos ao gênero. E de tal forma que, na modernidade, a vida social apresenta-se impregnada de etarismo (ageism). Tanto quanto de sexismo. Apenas o preconceito/discriminação contra a idade se apresenta de forma menos perceptível, mais sutil que o 
sexismo, porque mais naturalizado pela evidência dos registros da passagem do tempo nos corpos. E os corpos são de várias idades, em suas diferentes transformações e possibilidades, individuais e sociais.

Ao mesmo tempo, a sociedade capitalista vem mudando de referência social principal ao grupo para a referência crescente ao indivíduo. São expressão acabada disso as formas de regulação do Estado nacional moderno na sua prescrição de uma idade "certa" para cada participação ou pertinência social dos indivíduos e de alguma forma de sanção para a desobediência a essas prescrições legais. Tanto quanto uma ideia impositiva de realização pessoal concomitante, ou sobrepujando à dos ciclos - e pessoas - da vida familiar.

Por todo esse relativismo e transitoriedade de posições etárias que se tornam também geracionais é que, por suposto, se tem mantido teoricamente difícil a definição e análise do campo das relações entre as gerações e a sua inscrição teórica na visão articulatória com outras categorias relacionais, mesmo o fundamental gênero.

Em resumo, a grande questão que parece tolher muitos estudiosos é decorrente basicamente dessa variabilidade ou mudança de posições etária e geracional das pessoas e grupos no tempo. Na vida vivida, se somos sempre pessoas de um determinado sexo/gênero, raça/etnia e classe social, mudamos de idade - processo biossocial - e de expectativas sobre ela, a cada ano, ao mesmo tempo em que o nosso grupo etário vai assumindo posições geracionais diversas enquanto coorte geracional - embora não necessariamente enquanto geração social no sentido estrutural definido por Karl Mannheim (1928). O jogo de poder entre as gerações se desloca e se reinstala continuamente, causando a impressão de ausência de capacidade estruturante do social... Mas que escasso poder estruturante é esse, que atrai tantas regulações - legais, tanto quanto informais, consuetudinárias e ideológicas - e promove, documenta e narra a memória social, além de motivar, no processo da sua própria sucessão, muito do dinamismo social?

Como o objeto de subordinação etária ou geracional muda no tempo - tanto no sentido cíclico da vida ou trajetória dos indivíduos como no percurso histórico das sociedades -, isso torna pouco visíveis os mecanismos de dominação e subordinação social, assim como as formas de luta do segmento que procura libertar-se, porque ele é "individualmente" - enquanto pessoas e enquanto grupo etário - móvel. Ao mesmo tempo "mudando de 
lugar" parece, então, escapar aos mecanismos e propósitos da dominação capitalista - que hoje, muito consensualmente, situa-se em torno de três "eixos" teóricos: gênero, raça e classe social. Mas o modelo estrutural do conflito entre gerações e grupos de idade, ainda que teoricamente assim invisibilizado, realiza-se e persiste em seus efeitos, até mesmo em interseção com os já citados "eixos" - ou dimensões de atuação e de análise.

Tanto que, por outro lado, pode até mascarar, com discussões como a "luta contra a iniquidade geracional", problemas estruturais maiores (AttiasDonfut, 1995). Ao mesmo tempo, com a referida polissemia de uso da categoria geração, mais o campo teórico - e analítico - se complexifica.

\section{Usos da categoria "geração"}

Independentemente da larga utilização dessa categoria no cotidiano, em que passou a designar até as etapas do progresso técnico (por exemplo, maquinário de última geração), os usos do par conceitual idade/geração no campo da análise científica, particularmente no âmbito das ciências sociais, podem ser sintetizados segundo três perspectivas ou sentidos principais (Attias-Donfut, 1988; Delbes \& Gaymu, 1993) que terminam por ser, em parte, intercambiáveis, embora criticamente observados também em seus deslizamentos (glissements) de sentido (Attias-Donfut, 1988, 1991): coortes, grupos etários e gerações propriamente ditas.

Coorte é referência estatística ou demográfica e basicamente designa um conjunto de indivíduos nascidos em um mesmo intervalo de tempo, expostos a determinados eventos de caráter demográfico. Em princípio, entre as três noções, encerraria o sentido menos geral ou sociológico, mas não é assim para alguns estudiosos. Para Bengtson (1995), por exemplo, coorte é o que deveria ser usado no sentido social mais amplo, geração referindo-se apenas ao âmbito da família, no sentido genealógico. Bengtson (1995) critica duramente o uso de geração, pela imprecisão, propondo até, em seu lugar, o termo linhagem, porém ao mesmo tempo edita toda uma discussão teórica em que geração é inevitável - a paradigmática equidade entre as gerações.

A tradição antropológica é responsável pela segunda acepção de geração, que se expressa, basicamente, em termos de idades (grupos etários, categorias de idade, classes de idade etc.) referindo-se quase sempre à filiação, guardando um sentido ou uma função classificatória que inclui tanto as posições na família como na própria organização social mais ampla. Essa 
acepção tangencia outros sentidos não exclusivamente cronológicos, quando enfatiza atributos culturalmente definidos, como na proposta de Meyer Fortes (1984), de estágios de maturação.

Essa classificação primeira e fundante que as idades historicamente alcançam, em interseção com o sexo/gênero (Balandier, 1977), permanece na sociedade contemporânea e se mantém como gerações na família e (ou) etapas no curso da vida, idades biossociais para assunção de direitos e deveres que são cobrados, permitidos ou admitidos, mas também passíveis de contestação, tanto nas relações cotidianas como nas normas jurídicas e prescrições oriundas do Estado.

Derivam daí as "idades da vida", traduzidas hoje aproximadamente em infância, juventude, maturidade e velhice, mas que atravessaram o imaginário dos últimos séculos, registradas em ilustrações de publicações, capas de livros, almanaques, depois também nomeadas ou tratadas como "gerações", principalmente na atualidade. Essas "idades" tornaram-se também "ramos" de uma sociologia das gerações - sociologia da juventude, sociologia do envelhecimento...

O sentido mais plenamente sociológico, ou macrossociológico - geração, propriamente dita - designa um coletivo de indivíduos que vivem em determinada época ou tempo social, têm aproximadamente a mesma idade e compartilham alguma forma de experiência ou vivência, ou têm a potencialidade para tal.

Tanto o conceito como, sobretudo, uma estimativa dos limites ou justificativa de vigência social de uma geração - possibilidade de eficácia política ou cultural - no tempo, constroem-se ao longo de uma trajetória de reflexão sociológica que vem de Comte a Mentré (1920) e amadurece com Mannheim (1928), com um desenvolvimento paralelo e não diretamente comunicante com este, na proposta de Ortega (1923).

Mannheim (1928: 134) define geração em vários momentos e etapas de desenvolvimento do seu texto na Sociologia do conhecimento, sempre acentuando seu sentido histórico:

[...] indivíduos que pertencem à mesma geração [...] estão ligados

[...] a uma posição comum na dimensão histórica do processo social, [o que significaria uma predisposição para] um certo modo caracte- 
rístico de pensamento e experiência e um tipo característico de ação historicamente relevante (Mannheim, 1928: 135-136).

Embora esse seja o sentido básico de sua concepção, Mannheim não desvincula, evidentemente, geração e grupo de idade:

[...] o fenômeno social geração nada mais representa do que um tipo particular de identidade de situação de grupos de idade mergulhados num processo histórico social (idem: 137).

Situa, também, a base biológica da vida humana, para reforçar, pelo contraste, o sentido histórico dos fenômenos sociais:

Na verdade, o traço mais surpreendente do processo histórico parece ser o de os fatores biológicos básicos operarem duma forma latente e só poderem ser compreendidos através dos fenômenos sociais e históricos que constituem uma esfera acima deles (ibidem: 163).

Apresentadas alternativas de definições de geração que, em boa parte, confluem, duas questões básicas imediatamente se impõem e guardam intensa atualidade. Ao se observar que o mesmo contexto social não afeta igualmente todos os indivíduos de um grupo de idade e vivência classificado ou autoidentificado como geração, verifica-se que segmentos dessa geração podem assumir posturas e caminhos sociais diferentes, ou até opostos. É o caso de padrões ou de movimentos culturais que se manifestam diversamente na mesma época, ou de movimentos políticos, uns radicais outros conservadores, cada um reunindo indivíduos de idade aproximada num cenário social semelhante. Por outro lado, cada momento histórico se realiza com a presença simultânea de várias gerações que, mesmo contemporâneas, não têm as mesmas experiências e trajetórias de vida.

Mannheim detém-se criativamente sobre ambas as questões. Propõe a categoria "unidade de geração" para designar a potencialidade - ou não - de formação de "grupos concretos" em que se fracionariam as gerações e, por outro lado, incorpora a brilhante formulação de Pinder (apud Mannheim, 1928) sobre a "não contemporaneidade do contemporâneo":

Todas as pessoas convivem com pessoas da mesma e de diferentes idades [...]. Mas para cada uma o mesmo tempo é um tempo diferente [...] (Mannheim, 1928: 124). 
Na sociedade longeva que vem se constituindo nas últimas décadas - quando, cada vez mais frequentemente, coexistem quatro e até cinco gerações na mesma família, pois, desse ponto de vista, as gerações quase não se substituem, se sucedem (Attias-Donfut, 1993) -, a reflexão de Mannheim constitui-se em importante ponto de partida analítico e inspiração para a pesquisa.

Ao enunciar os pressupostos básicos de uma teoria de gerações - até hoje a mais completa e elucidativa -, Mannheim dedicou-se, nesse campo, concretamente, a estudos sobre a juventude; aos jovens como agentes "naturais" da mudança social, ou aos jovens problematizados como membros de grupos ou facções políticas radicais (Mannheim, 1961).

\subsection{Os jovens}

Será sobre a juventude, o segmento etário privilegiadamente estimulado ao novo e à mudança e, portanto, com o potencial maior de expressar-se enquanto geração social, que todos, durante largo tempo, apenas se debruçarão. E continuam a debruçar-se. Apesar do reconhecimento, desde o próprio Mannheim (1961), de que essa potencialidade da juventude se dá por seu maior espírito de aventura e descompromisso com o status quo, mas que depende da natureza da sociedade o uso delas.

Também Eisenstadt (1976) longa e amplamente analisa os jovens e os movimentos juvenis, não em termos centrais de geração social, como o título de seu livro clássico De geração a geração promete. Eisenstadt centra-se em grupos etários e em graus etários, no geral construindo uma panorâmica de grupos jovens em suas formas básicas de organização e inter-relação com as "gerações" - essas últimas no sentido de posições na família. Preocupado em analisar a função dos grupos etários na interação social, Eisenstadt (1976: 32) discerne uma possível origem e razão de ser desses grupos, assinalando que eles

[...] se originam das tensões entre as gerações e sua função é descobrir válvulas de escape para estas tensões [...]. [Nesse sentido], podem funcionar como mecanismos de ajustamento secundário ou, em alguns casos, como ponto de partida para a formação de grupos anormativos (idem: 32).

E segue explicando: 
Os grupos etários tendem a surgir quando a estrutura da família, ou do grupo de descendência, bloqueia as oportunidades dos membros mais jovens de alcançar status social dentro da família [...] (ibidem: 233).

Mas refere uma diversidade de situações, pois

[...] os grupos etários que existem sob estas condições diferem consideravelmente daqueles existentes [...] sob critérios universalistas de integração dos sistemas sociais (ibidem: 29),

os quais ensejam a constituição de grupos etários homogêneos e intermedeiam a transição da família para a sociedade mais ampla.

Se, em fases históricas anteriores, os grupos etários já tinham afluência ou visibilidade, na contemporaneidade, principalmente nas cidades, grassam as "tribos" (Maffesoli, 1987; Machado Pais, 2004), que dão vazão às mais variadas formas de expressão de pertencimento grupal, atingindo modificações inusitadas até do próprio corpo. Os jovens diferenciam-se cuidadosamente das gerações mais velhas, dividindo-se estas entre a crítica a eles e a que serve de modelo para um aprendizado imitativo...

Entretanto, com a ampliação significativa das formas de sociabilidade não familial, essa tendência atual à formação ou agregação em grupos etários vem atingindo também os mais velhos, que passam a constituir objeto recente de visibilidade social e exposição ao consumo capitalista de serviços, paralelamente à ampliação de uma esfera de liberdade individual, em inédita expressão coletiva nos grupos de lazer e cultura para a "terceira idade" e, inesperadamente, na política, no movimento dos aposentados.

Também com foco preciso nos grupos jovens, se começou a discutir geração no Brasil nas décadas de 1960 e 1970, o que correspondeu à referida tendência praticamente mundial, caracterizada por um afã interpretativo diante dos numerosos e amplos movimentos juvenis então em ação: estudantis, hippies, contra a guerra do Vietnã, a "segunda onda" do feminismo, movimento negro etc. Registra-se variada produção sobre uma possível geração jovem, referenciada, sobretudo, à categoria "estudante" e a um quase teoricamente prescrito "conflito de gerações" (Foracchi, 1972; Ianni, 1963; Guilhon Albuquerque, 1977). 
A retomada ou redescoberta da discussão sobre "solidariedade entre as gerações" só se daria nos anos 1990, mais em breves referências que em trabalho teórico (Britto da Motta, 2003). Ocorre, com ênfase, a propósito da preocupação social com o contraditório - desejável e, ao mesmo tempo, indesejado... - alcance da longevidade. E dar-se-á, em sua dupla vertente, em termos classificatórios de gerações e em suas inter-relações. Por um lado, a expectativa de solidariedade privada, a sempre esperada e crescentemente induzida solidariedade na família, nestes tempos de desemprego estrutural e desincumbências sociais do Estado; mas também, e pelas mesmas razões estruturais, uma atualmente inescapável discussão sobre a solidariedade pública entre as gerações. Ao mesmo tempo, ensaiando-se retomar, de forma ampliada, uma ênfase, quase em moldes de antecipado enredo de "ficção científica", no conflito entre "gerações" jovens e velhas, agora a propósito de uma vagamente preconizada e nunca realizada equidade entre as gerações (Bengtson \& Acchenbaun, 1993).

\subsection{Os velhos}

Só bem mais recentemente, entre as décadas de 1980 e 1990, esse outro grupo geracional, o dos velhos, é alçado a objeto de estudo, por uma razão, bem mais que científica, diretamente utilitária. Passam a ser considerados, pelo seu acelerado crescimento relativo e sua duração maior de vida, um "problema social" que é preciso resolver; do mesmo modo como "problemas" teriam sido os jovens contestadores da década de 1960 e os "menores" em "erro social" dos anos 1970.

Lenoir lembra-nos como é difícil resolver as questões que aparecem como problemas sociais, porque eles "[...] são instituídos em todos os instrumentos que participam da formação da visão corrente do mundo social" (1998: 62 , grifo do autor), quer se refiram às regulamentações ou políticas, quer às categorias de percepção do fenômeno, que geralmente se consubstancia em uma "população". Que fica representando, naquele momento, uma "crise" para o sistema social, quando, em verdade, este é que deveria ser posto em questão. Ao longo do tempo, transformando-se o contexto social, o mecanismo vai se repetindo, novos "problemas" vão se apresentando...

A demografia assinala que há, proporcionalmente, cada vez menos crianças - o que aponta para uma provável dificuldade de reposição populacional no futuro. Anuncia também o "pior", os velhos aumentam em número e longevidade, o que municia certos gestores sociais a argumentar que isto pode 
levar à "quebra" do sistema previdenciário e pôr em perigo a própria reprodução da sociedade. Estes são dos mais recentes "problemas sociais". E no centro deles estão, afinal, os velhos. A "geração" que inquieta, enquanto vai se desdobrando em anos e diversidades, e enseja uma nova e interessante questão teórica, também existencial e política: entre 60 e 110 anos de vida, que percurso geracional pode ser traçado? Quantas "gerações" de veIhos estão coexistindo neste novo espaço cronológico e social de 50 anos? Qual a "contemporaneidade" possível entre elas?

Entre percepções e tentativas de definir semelhanças e diferenças entre "velhos jovens" e "velhos mais velhos", é importante ter em conta outra observação de Lenoir (1998: 71-72):

A "velhice", assim como a "juventude", não é uma espécie de característica substancial que acontece com a idade, mas uma categoria cuja delimitação resulta do estado (variável) das relações de força entre as classes e, em cada classe, das relações entre as gerações, isto é, da distribuição do poder e dos privilégios entre as classes e entre as gerações.

E os gêneros, acrescentaríamos... E o trabalho teórico - tanto quanto o de pesquisa, em seguida - seria procurar discernir-se que processos sociais ensejam essas delimitações, porque elas são essenciais nos enunciados e definições de políticas públicas aplicadas às várias idades, assim como aos âmbitos da pesquisa empírica e, consequente, análise das relações de solidariedade e de conflito, tanto entre os indivíduos como entre as gerações sociais.

As gerações, como as classes sociais, não existem isoladamente, mas em referência mútua, contraposição ou até oposição umas às outras. Uma geração é ou se torna aquilo que o jogo de poder enseja nas relações com as outras. Esse movimento ocorre segundo as condições sociais vigentes em cada momento ou tempo social e o modo possível de apreensão e resposta dos atores sociais geracionais. É preciso lembrar sempre que, no interior de cada grupo geracional ou de idade, constroem-se representações, identidades e situações sociais que se confrontam com as de outros grupos ou categorias sociais. Ao mesmo tempo, essas relações realizam-se em articulação com condições identitárias definidas a partir de outras dimensões relacionais, principalmente a de gênero e a de classe social (Britto da Motta, 1999). 
Mas este é um enfoque teórico comumente "esquecido" nos estudos e pesquisas sobre idades e gerações, que, nada raro, cingem-se ao enfoque, individualizado, de uma só geração. Ao mesmo tempo, naqueles trabalhos que se centram nas relações de gênero, inclusive os de origem feminista, a condição etária ou geracional é quase invariavelmente omitida, ainda que a articulação analítica com as categorias classe social e raça já seja regular e proveitosamente realizada.

\section{Violência, gênero e idade}

Dos grandes temas e questões da atualidade, o envelhecimento e sua personificação nas figuras da idosa e do idoso vem sendo o de expressão social e analítica mais tardia.

Politicamente ausente na grande expansão mundial de movimentos nas crises dos anos 1960 (movimentos estudantis, movimento hippie, feminista, negro etc.), no Brasil vai palidamente aparecendo no contexto da retomada democrática dos anos 1980, porém bem atrás do que estavam sendo as expressões feminista, negra e jovem do movimento social. Firma-se, afinal, nos anos 1990, fruto de um visível crescimento demográfico e, como no caso dos outros segmentos sociais, também através de movimentos: o político, dos aposentados, de luta pela afirmação da previdência pública, e o cultural/comercial dos programas, clubes e universidades "para a terceira idade". Mas, ao mesmo tempo, firmando-se também como o referido "problema": objeto de discussão sobre os repetidamente alegados déficits da Previdência e a necessidades de "reforma da Previdência", pelo Estado e o "perigo" que a crescente longevidade, com o seu extenso cortejo de veIhos, representaria para a própria reprodução social.

Trajetória que se desenrola paralela à da maior visibilidade teórica da categoria geração, fundamento analítico infugível na discussão de situações sociais referentes às idades em sua comunidade de vivências e experiências, mas a derradeira categoria relacional a ser cientificamente trabalhada nas pesquisas atuais, quando uma articulação analítica gênero, classe e raça torna-se de uso rapidamente consensual, como já referido (Britto da Motta, 1999).

Em conformidade com essa percepção lenta, em vários aspectos ou situações da vida social a existência e a significação dos idosos neles também é percebida tardiamente, ou quase nunca. É o caso exemplar da violência, particularmente a violência contra a mulher idosa. 
Se a luta atual contra a violência tem, afinal, um crescente e justificado reconhecimento social, apoiada por políticas públicas, propostas, em maioria, pelo movimento feminista, a violência contra as mulheres não se restringe à vitimização daquelas em idade jovem, no período reprodutivo, como retrata a grande maioria dos trabalhos e assumem as instituições sociais. Ao contrário, essa violência continua e ganha novas formas velhice adentro. Sendo, neste caso, a expressão gritante das relações intergeracionais, tanto quanto das relações e desigualdade de gênero, porque exercida, como começam a demonstrar as pesquisas, majoritariamente por fiIhos, filhas e netos sobre suas mães e avós.

Vive-se, no Brasil, um tempo em que a violência parece ter crescido e estar por toda parte. Com maior intensidade e novas formas. Mas o que será realmente novo nesse quadro? Além de um redobrado afã em estudar ou propor formas de prevenção ou contenção do fenômeno?

Adorno e Cardia (1999) historiam uma trajetória brasileira de recurso à violência nas relações cotidianas desde a sociedade agrária tradicional. A violência como modo conhecido e socialmente aceito de solução de conflitos. $\mathrm{Na}$ atual produção feminista de denúncia social e teorização específica sobre formas e intensidade - que também parecem crescentes - de violência contra a mulher, pode-se tangenciar ou plenamente confirmar essa informação sobre a presença antiga e ubíqua da violência nas relações cotidianas, inclusive no apregoado "lar doce lar" - e não apenas no Brasil - explicando-a como constitutiva das próprias relações de gênero, expressão da legitimação da dominação patriarcal sobre as mulheres (Saffioti, 1994).

De logo se percebe que essas referências, assim como as próprias políticas adotadas, cingem-se à situação das mulheres jovens e adultas plenas, isto é, das não velhas. Fica esquecido que as mulheres participam, física e socialmente, de diferentes grupos de idade, e mais, de que em todas essas etapas de vida, elas são, pelo menos potencialmente, objetos de violência - apenas essa violência costuma ter especificidades segundo a sua faixa de idade e, em parte, a motivação do agressor(a), além de ter intensidades de repercussão social também diferenciadas.

O caso das mulheres idosas, frequentemente silenciado ou "abafado" pela família - ciosa de sua imagem social de proteção e tranquilidade - quando ocorre no âmbito doméstico, apresenta motivações e manifestações múltiplas, em que a sexual é a mais rara e os maus-tratos, a negligência e a 
espoliação financeira, as mais comuns. Garrido (2004) reporta várias modalidades de violência, percebidas através do atendimento de equipes do Programa Saúde da Família (PSF) na Bahia, em que se destacam duas. Primeiro, em relação a exagero de carga de trabalho:

A mulher idosa queixa-se aos profissionais de saúde de sobrecarga de responsabilidades, pois precisam cuidar de netos e/ou bisnetos. $\mathrm{Na}$ visão dos técnicos, as responsabilidades e os aborrecimentos resultantes dessas atividades contribuem para o agravamento de enfermidades crônicas, a exemplo da hipertensão arterial. Essas vicissitudes são geralmente comentadas nos grupos educativos de diabetes e hipertensão, nos encontros de idosos ou nas visitas domiciliares [...] (Garrido, 2004: 87).

A segunda modalidade condensa-se em relato - de sentido muito geral e ao mesmo tempo grave - de suspeita de assassinato de uma senhora idosa, eliminação geracional, que a classificação de violência de gênero é insuficiente para caracterizar. Relata Garrido:

Os profissionais da Unidade do PSF foram comunicados pelos vizinhos daquela senhora de que um morador estaria tentando assassinar a própria mãe, utilizando-se de "chumbinho" para envenená-la (idem: 88).

Transcreve o depoimento da visitadora do programa:

Essa senhora mesmo. Até a neta dela me disse: “Olhe B., eu tô vendo a hora de acontecer alguma coisa com minha avó e o povo achar que minha mãe compartilhou." Ele é violento. [...] Quando nós fomos fazer a visita, ela fazia queixa dele assim, ó: "Ô minha filha, me tire daqui que esse homem vai me matar." [...] Porque vieram denunciar que ela tinha dado uma crise que ele tinha dado chumbinho (ACS 01) (ibidem: 87).

E continua Garrido:

Antes disso, vários episódios de violência contra a mãe e a esposa já vinham ocorrendo, resultando, inclusive, em internamentos com lesões graves. Esta senhora veio a óbito, porém não houve queixa formal do fato e tampouco foi possível confirmar a suspeita de envenenamento (ibidem: 88). 
E arremata, deixando-nos um elemento para reflexão e mobilização:

Os vizinhos e profissionais de saúde tiveram, como possíveis barreiras de impedimento, a esfera privada do evento e o receio de pôr em risco a segurança pessoal (ibidem: 88 , grifo da autora).

Realmente, sobre a violência contra os idosos muito poucos se manifestam. Na vida cotidiana, mas também na política e na pesquisa acadêmica. No Brasil, algumas vozes se destacam, mais ou menos individualmente, a exemplo de Camarano (2004), Debert (2001), Debert \& Gregori (2008), Faleiros $(2007,2009)$ e Minayo (2003). Fala mais sistematicamente apenas a gerontologia. Entretanto, guardando suas origens na medicina e no serviço social, apresenta escassa expressão teórica quanto ao contexto e ao tom em que se dão as relações sociais e, portanto, também as ações violentas.

Esses trabalhos, sim, são razoavelmente numerosos, pelo menos afirmativos da existência do fenômeno "violência contra a pessoa idosa". Às vezes literalmente assim enunciados, não raro despidos do conteúdo de gênero. Têm o mérito de incluir o problema como questão, que é, também de saúde pública, mas nem sempre acompanhados de alguma pesquisa - o que significaria a possibilidade de um contato direto e mais amplo com a realidade social. São, em grande parte, classificatórios, informando extensamente tipos e formas de violência, seguidos de indicações sobre os recursos disponíveis em políticas públicas para fazer frente à questão; quase sugestões de autoajuda.

Um ponto comum entre os estudos sociológicos sobre violência e os estudos diretamente feministas sobre esse mesmo tema é justamente a omissão em relação à violência contra esse segmento social frequentemente invisibilizado: os idosos. Além da ausência de uma consequente extensão de enfoque teórico que os contemple, que seria, além do de gênero, o das relações entre as gerações, tanto quanto o concomitante projeto possível de ações públicas para prevenir e combater essa agressão.

O problema é que, além da histórica cegueira da sociologia em relação à subordinação social das mulheres e às relações de gênero, o feminismo não costuma notar as mulheres idosas (Britto da Motta, 2002; Woodward, 1995). Não se detém diante delas, para alcançar a percepção de que também são alvos privilegiados de violência, de diferentes, repetidas e convergentes formas de violência, e que seus agressores - como vêm demons- 
trando as pesquisas mais recentes (Faleiros, 2007, 2009; Menezes, 1999; Minayo, 2003) e as próprias estatísticas de delegacias do idoso - são primordialmente os filhos e as filhas, às vezes os netos. Portanto, pessoas de gerações mais jovens. Sobretudo homens, mas mulheres também.

O feminismo, habitualmente, não enxerga os diferenciais de idade, as "localizações" das gerações na estrutura social e das pessoas no tempo, posições que gestam as relações entre as gerações. E que estas, do mesmo modo como aquelas, constituídas pelos já reconhecidos campos analíticos gênero, raça e classe social - também são relações de poder. Como tais, não se realizam sem conflitos. Por aí devem ser também identificadas, e não apenas pela requerida e alternativa solidariedade.

Evidente que o enfoque analítico da violência contra as idosas converge para as relações de gênero, principalmente no caso da violência doméstica, a mais comum a esse segmento geracional - mas perde eficácia interpretativa e explicativa se se detiver apenas aí. A violência praticada por esses homens, filhos (maioria dos agressores), mas também filhas e, não raro, netos contra essas mulheres (maioria entre os idosos agredidos) que são também suas mães ou avós, é expressão e consequência de vivências ou conflitos que se armam, basicamente, na esfera das relações intergeracionais.

Embora possam também ser, alternativamente, mas na mesma clave geracional, consequências ou revides de más atuações maternas, de maus-tratos dessas mulheres sobre os filhos, no passado. A violência contra as idosas deve ser vista/analisada como fenômeno que se dá em âmbito geracional, que ganha maior visibilidade por conta da situação de gênero: exercese preponderantemente sobre as mulheres - pelo próprio fato demográfico de que elas são maioria, mesmo - porém, devido, igualmente, à esperada "fragilidade" feminina - física, afetiva e social.

Ou analisada ao reverso: uma violência de gênero que se realiza majoritariamente no contexto geracional. Por isso, é infugível a análise dos acontecimentos no contexto articulado dessas duas dimensões, de gênero e de gerações.

Como isto não costuma acontecer, é de se perguntar: por que tanta dificuldade em se perceber a condição geracional e seus embates?

Lembre-se que Bourdieu (1983), no conhecido artigo "A juventude é apenas uma palavra", já dizia: 
Na divisão lógica entre os jovens e os velhos, trata-se do poder, da divisão (no sentido de repartição) dos poderes. As classificações por idade (mas também por sexo, ou, é claro, por classe...) acabam sempre por impor limites e produzir uma ordem onde cada um deve se manter, em relação à qual cada um deve se manter em seu lugar (idem: 112, grifo do autor).

E sobre os conflitos entre gerações:

Uma coisa muito simples e na qual não se pensa é que as aspirações das sucessivas gerações de pais e filhos são construídas em relação a estados diferentes da estrutura de distribuição de bens e de oportunidades de acesso aos diferentes bens: aquilo que para os pais era um privilégio extraordinário (na época em que eles tinham 20 anos, por exemplo, havia uma pessoa entre mil da sua idade e do seu meio que possuía um automóvel) se tornou banal, estatisticamente. E muitos conflitos de gerações são conflitos entre sistemas de aspirações constituídos em épocas diferentes (ibidem: 118).

Também Lenoir (1998: 68), em sua análise das categorias de idade, deixa bem claras as manobras e lutas pelo poder entre as gerações: "[...] o que está em questão é a definição dos poderes associados aos diferentes momentos do ciclo da vida [...]." E nessa definição de idades, sempre ligadas a um lugar e uma definição no espaço social, Lenoir adverte ao sociólogo para levar em consideração, em sua análise

não só as relações de força entre as gerações e entre as classes sociais, mas também as representações dominantes das práticas legítimas associadas à definição de sua faixa etária (idem: 68).

Em relação à velhice, lembra que essa definição é tão arbitrária quanto a de outra qualquer idade, porém no caso tem o agravante de que se tornar "velho" significa, em verdade, tornar-se

velho demais para exercer determinada atividade ou ter acesso, de forma legitima, a certas categorias de bens ou posições sociais (ibidem: 68, grifos do autor).

E muito da violência contra os velhos evidencia-se, deve-se à recusa, consciente ou até instintiva destes, a ocupar o (não)lugar social e vital que os 
mais jovens enxergam para eles e Ihes designam: de abdicar da posse dos bens materiais - da aposentadoria, da pensão, da casa - ou até de retirar-se da própria vida, incômodas criaturas que atravancam os espaços da casa e as redes de relações, e "dão trabalho".

Ao lado disto, há uma tendência, inerente ao imaginário social, a construir representações ou tipos sociais ideais em relação às idades da vida. Principalmente àquela idade predileta, a que resumiria os anseios mais caros de realização de vida dos grupos sociais. É o que ocorre em relação aos adultos jovens. Como expressa Foracchi (1972):

A plenitude do status, a amplitude de participação, a identificação completa com os ideais que a sustentam são condições que definem o adulto perante a sociedade em que vive (idem, p. 19). [E mais:] Cada etapa [geracional] é [...] compreendida em contraposição e em contraste com a anterior ou com a subsequente (ibidem: 19).

Em verdade, há uma rejeição social, histórica, à condição de velhice, personificada nos idosos, que nas objetivações próprias da modernidade se constitui, ao mesmo tempo, em negação do passado e do futuro; rejeição a uma figura de certo modo ambígua, que remete ao mesmo tempo ao passado (ao que já passou e se tornou "superado", "inútil" e oneroso) e ao futuro; o futuro que ele aponta e se nos afigura à espera de cada um - doenças, perdas, dependência e fealdade; senilidade e proximidade da morte. Que desencadeia uma pulsão a "exorcizar" esse fantasma do futuro, afastando-se dele ou até ensaiando destruí-lo (Britto da Motta, 1998).

Dimensão subjetiva a que se acopla, inextrincavelmente, aquela outra, material/objetiva, da divisão social dos bens e dos poderes, nunca deixados de ser afigurados como escassos. A história e a antropologia documentam isso, que a arte, o cinema podem até romantizar, mas para, ao mesmo tempo, demonstrar que são muitos os Narayamas.

Afinal, entre o descarte, real ou simbólico, dos velhos no passado (Rifiotis, 1998; Seeger, 1980) e o apossamento atual de suas aposentadorias e pensões por filhos e outros parentes, e por empréstimos consignados fraudulentos, deixando-os (ações públicas e privadas) à míngua, há diferença apenas de tempo social e geografia.

Faleiros (2007) retrata, com propriedade, muito do quadro brasileiro atual: 
[...] uma sociedade que, ao mesmo tempo, produz desemprego e condições precárias de vida e valoriza o consumo, acirrando-se os conflitos de gerações. Essa precariedade, articulada à redução do Estado e à competitividade, leva os conflitos sociais para dentro de casa, de forma muito explícita, com a pressão por sobrevivência, por atender às exigências de consumo e mesmo ao tráfico/consumo de drogas (idem: 369).

Mesmo no cotidiano mais tranquilo das nossas "famílias bem estruturadas" atuais, ainda assim pode se notar - na observação cotidiana e na pesquisa empírica - a comum e pressionante tentativa de interferência, ou até de ingerência, por parte dos mais jovens, sobre a vida dos "seus" idosos; principalmente das mulheres. Atividades, saídas, uso do dinheiro, até vida sexual-afetiva, tudo é acompanhado pelo menos com humor crítico e, não raro, tentativamente regulado - e os motivos podem ser, ou não, expressão de real cuidado e afetividade.

De qualquer modo - e por melhor que esta seja a intenção -, trata-se de um protecionismo cerceador, que tem contribuído para que as mulheres idosas aspirem e realizem a possibilidade, socialmente recente, de morarem sozinhas. Ato libertador, nem sempre totalmente eficaz... Principalmente para as muito idosas (Britto da Motta, 2003).

E qual o mecanismo das relações entre gerações?

Independentemente de seu conteúdo afetivo, diferentemente das relações de gênero, as relações entre as gerações histórica e cotidianamente desenvolvem-se na direção de substituição e até de aniquilamento. Pela morte biológica e pela "morte" ou olvido social. As relações violentas constituem-se no auge da realização disto.

O processo de substituição geracional é atenuado - inclusive quanto à sua percepção - pelo fato de que se realiza no decorrer do tempo. Um tempo às vezes longo, em um contexto em que se espera e, evidentemente, também se realizam relações de solidariedade e afeto. Solidariedade que se desenvolve tanto por obrigação social, pública, formalizada por injunção do Estado, como pela presença próxima, familial, às vezes contraditória, de uma afetividade positiva que, ao mesmo tempo, pode se transmudar, segundo diferentes situações e temporalidades, em sentimento ou ação negativa. 
As substituições dão-se em todas as dimensões: dos papéis estruturais na família; nos cargos/ocupações no trabalho, onde guardam competitividade mais contundente (Godard, 1993; Grun, 1999); nos postos/situações individualizadas, na política; nos grupos geracionais na produção cultural (também na ação política) e na economia.

A crescente longevidade atual enseja menos substituições "naturais", o que é muito perceptível no âmbito da família: os indivíduos permanecem muito mais tempo em seus papéis geracionais - de avós, pais, netos etc. -, além de atingirem um número maior de papéis, de certa forma superpondoos. Sendo-se, simultaneamente (e por mais tempo) bisavô, avô, pai, filho... E o ser tudo isto é também uma condição que evidentemente se desenvolve na dimensão de gênero e conforme o habitus de classe (Bourdieu, 1990) em determinado tempo social. Ora, exatamente por essa amplitude ou heterogeneidade identitária é que podemos repetir, com Mannheim, que "o mesmo tempo" histórico não é igual para todos. O que significa que as unidades de geração poderão apresentar características diferentes também segundo as várias pertinências identitárias de gênero e de classe social dos que as compõem.

A existência infugível da condição geracional é também expressa por AttiasDonfut:

L'existence sociale de la génération ne réunifie guère les divisions sociales de classe et de sexe; elle s'inscrit dans leur structuration même et y superimpose les divisions d'âge et de génération, investies de la fonction spécifique de marqueurs du temps social (1988: 235).

\section{O que revela a pesquisa}

Como ilustração possível das possibilidades explicativas de uma análise do ponto de vista das relações entre as gerações, analisamos, de modo exploratório, um tempo que foi vivido por idosos no Estado da Bahia, de forma tornada semelhante pela presença da violência.

Em acompanhamento não sistemático do noticiário, na imprensa de Salvador, sobre violência contra idosos neste estado, foram localizados 84 casos, entre 2001 e 2008, dos quais 46 de danos diretos maiores: encarceramentos, espancamentos, exploração financeira e até morte, perpetrados principalmente por parentes, vizinhos e conhecidos. 
Evidentemente, são os casos mais gritantes, os que vão parar nas delegacias de polícia e nos jornais diários, no trânsito para soluções ou resoluções mais imediatas e radicais, os que constituem a camada mais sensível da "ponta do iceberg". Porque os mais "comuns", os que aparentemente "podem esperar" a tramitação na delegacia especializada de atendimento ao Idoso são muito mais numerosos - apesar de sabidamente subnotificados. Basta comparar: oito dias depois da inauguração da Delegacia Especial de Atendimento ao Idoso (Deati/BA), em 2006, já eram 70 as denúncias; em 7 semanas já eram 639 (Bernardo, 2006). Passados dois anos, em setembro de 2008, somavam 4.508 (Deati, 2006-2008).

Nessas notícias de jornais, de logo uma certa surpresa: muitos homens também agredidos. Igualmente surpreendente o alto número de vizinhos e conhecidos como agressores (11 casos), rivalizando em número com os mais próximos na família: 9 filhos, 1 filha (com o genro), 1 filho e 1 filha adotivos, 3 enteados, 6 netos. Também 2 sobrinhos e 1 sobrinha. Muitos desconhecidos, também: assaltos a casas onde os idosos moram ou estejam, no momento, sozinhos (14 casos). Motivação evidente...

As idades desses agredidos variam entre 60 e 100 anos e a dos agressores, entre 9 e 46 anos. Mas, principalmente, entre 18 e 30 anos (18 ocorrências). Alguns desses casos se assemelham aos narrados por outros pesquisadores, como Garrido (2004) e Debert (2001). Por exemplo, o de D. Clara, 84, vítima de maus-tratos pelo sobrinho de 34 anos. Uma denúncia anônima ao Ministério Público revelou, também que ele "é acusado de tomar o cartão de saque da aposentadoria da tia e de estar retirando o dinheiro há seis meses sem repassar nada a ela". A idosa contou: "Ele me deixava presa, eu ficava sem comer, sem dinheiro e tinha medo que ele me envenenasse". Acrescentou que quem tomava conta dela era uma vizinha (A Tarde, 2007b).

Também mantida presa em casa, obrigada a realizar as tarefas domésticas e agredida constantemente pelo neto de 28 anos, D. Araci, 86 anos, declarou: "Eu tenho medo dele. Ele é muito bruto comigo. Ficaria feliz se fosse embora para outra casa". Mas ao final, pediu à polícia: "Não quero que meu neto seja preso" (A Tarde, 2007a).

Especialmente pungente é o caso da senhora de 73 anos, maltratada seguidamente pelo neto de 20. Após três dias de cárcere privado, encontrada bastante ferida, pediu que ele não fosse preso porque, apesar de bater nela com frequência, era sua única companhia diária ( $A$ Tarde, 2006). 
No caso das denúncias feitas ao Deati de Salvador (instalada em 31 de julho de 2006), entre agosto daquele ano e agosto de 2008 as estatísticas correspondem, grosso modo, às tendências encontradas nas referidas notícias de jornais: filhos e vizinhos são os que mais agridem, porém havendo ainda um percentual muito alto de "outros" agressores não especificados (Tabela 1).

Tabela 1

Relação dos agressores(as) com as vítimas. Salvador, 2006-2008

\begin{tabular}{|c|c|c|c|c|c|c|c|c|c|c|}
\hline \multirow{2}{*}{$\begin{array}{l}\text { Sem/Ano } \\
\text { Agress. }\end{array}$} & \multicolumn{2}{|c|}{ 20 Sem/2006 } & \multicolumn{2}{|c|}{ 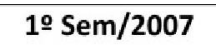 } & \multicolumn{2}{|c|}{ 2ㅇ Sem/2007 } & \multicolumn{2}{|c|}{ 10 Sem/ 2008} & \multirow{2}{*}{$\begin{array}{c}\text { Total } \\
\mathrm{N}\end{array}$} & \multirow{2}{*}{$\begin{array}{l}\% \\
\%\end{array}$} \\
\hline & $\mathbf{N}$ & $\%$ & $\mathrm{~N}$ & $\%$ & $\mathrm{~N}$ & $\%$ & $\mathbf{N}$ & $\%$ & & \\
\hline Cônjuge/Comp. & 91 & 6,72 & 56 & 4,01 & 87 & 5,41 & 79 & 4,64 & 313 & 5,16 \\
\hline Filhos & 456 & 33,67 & 338 & 24,22 & 432 & 26,87 & 465 & 27,36 & 1.691 & 27,92 \\
\hline Irmãos & 27 & 1,99 & 53 & 3,80 & 62 & 3,85 & 75 & 4,41 & 217 & 3,60 \\
\hline Netos & 56 & 4,13 & 57 & 4,08 & 55 & 3,42 & 62 & 3,64 & 230 & 3,80 \\
\hline Genros/noras & 46 & 3,39 & 58 & 4,15 & 78 & 4,86 & 93 & 5,47 & 275 & 4,54 \\
\hline Outros/parentes & 73 & 5,40 & 93 & 6,66 & 240 & 14,92 & 118 & 6,94 & 524 & 8,65 \\
\hline Vizinhos & 291 & 21,50 & 374 & 26,79 & 395 & 24,56 & 407 & 24,00 & 1.467 & 24,21 \\
\hline Outros & 314 & 23,20 & 367 & 26,29 & 259 & 16,11 & 400 & 23,54 & 1.340 & 22,12 \\
\hline TOTAIS & 1.354 & 100,00 & 1.396 & 100,00 & 1.608 & 100,00 & 1.699 & 100,00 & 6.057 & 100,00 \\
\hline
\end{tabular}

Fonte: Deati/BA (2006-2008). Dados organizados por Eulália Azevedo para o projeto Um palco de múltiplas vozes.

Os dados da Deati, infelizmente, não cruzam o sexo dos agressores com o dos agredidos, de modo que sem uma pesquisa direta nos BOs só teremos informações que confirmam (entre o segundo semestre de 2006 e o primeiro de 2008 ) o número mais alto de mulheres vitimadas $(57,68 \%)$ (Tabela 2 ) e o total maior de homens agressores (59,57\%). Sem deixar de notar, entretanto, o percentual alto $(40,43 \%)$ de mulheres também agressoras (Tabela 3), o que evidencia, mais uma vez, o conteúdo geracional da ação.

Tabela 2

Número de idosos(as) vítimas de violência. Salvador, 2006-2008

\begin{tabular}{c|c|c|c|c}
\hline \multirow{2}{*}{ Anos/semestre } & \multicolumn{2}{|c|}{ Mulheres } & \multicolumn{2}{c}{ Homens } \\
\cline { 2 - 5 } & $\mathbf{N}$ & $\%$ & $\mathbf{N}$ & $\%$ \\
\hline 20 Sem/2006 & 709 & 57 & 531 & 43 \\
10 Sem/2007 & 776 & 61 & 500 & 39 \\
20 Sem/2007 & 831 & 56,5 & 639 & 43,5 \\
10 Sem/2008 & 922 & 56,6 & 706 & 43,4 \\
TOTAL & $\mathbf{3 2 3 8}$ & $\mathbf{5 7 , 6 8}$ & $\mathbf{2 3 7 6}$ & $\mathbf{4 2 , 3 2}$ \\
\hline
\end{tabular}

Fonte: Deati/BA (2006-2008). Dados organizados por Eulália Azevedo para o projeto Um palco de múltiplas vozes.

Por fim, dados de pesquisa de Faleiros (2009) permitem uma ampla visão de 27 capitais brasileiras em 2005, em relação à perspectiva geracional e, em grande parte, familial da vitimização de idosos. 
Tabela 3

Número de agressores(as) de idosos(as). Salvador, 2006-2008

\begin{tabular}{c|c|c|c|c}
\hline \multirow{2}{*}{ Anos/semestre } & \multicolumn{2}{|c|}{ Mulheres } & \multicolumn{2}{c}{ Homens } \\
\cline { 2 - 5 } & $\mathrm{N}$ & $\%$ & $\mathrm{~N}$ & $\%$ \\
\hline 20 Sem/2006 & 546 & 40 & 805 & 60 \\
10 Sem/2007 & 541 & 38,8 & 853 & 61,2 \\
20 Sem/2007 & 668 & 41,9 & 923 & 58,1 \\
1ㅇem/2008 & 688 & 40,3 & 1019 & 59,7 \\
TOTAL & $\mathbf{2 4 4 3}$ & $\mathbf{4 0 , 4 3}$ & $\mathbf{3 6 0 0}$ & $\mathbf{5 9 , 5 7}$ \\
\hline
\end{tabular}

Fonte: Deati/BA (2006-2008). Dados organizados por Eulália Azevedo para o projeto Um palco de múltiplas vozes.

Infelizmente, também aqui não é especificado o sexo das vítimas. Em apenas uma dessas capitais (Palmas) os filhos e filhas não foram os maiores agressores. Analisa Faleiros (2009: 241): “Os filhos são, em média 39,01\% de agressores [...] e as filhas, em média, 15,71\%." Em Salvador, filhos e filhas agressores somam $64,13 \%$ (sendo os filhos $41,31 \%$ ) e netos e netas $5,43 \%$. Em algumas outras capitais, o número de netos (sem discriminar o sexo) agressores é grande, o que provavelmente motivou o comentário de Faleiros (2009: 240) sobre uma "repetição de atos de forma transgeracional." Algo que merece uma pesquisa posterior.

Espero ter deixado evidente, nesta análise exploratória, o conteúdo geracional intenso presente nas violências contra os idosos, em particular contra a idosa, e que o pleito por ampliação do escopo teórico de análise da violência contra o segmento idoso, com ênfase em relação à mulher, para incluir a categoria geração no seu valor heurístico e na sua transversalidade com o gênero, não pareça significar a adesão conceitual ou empírica à temática da violência doméstica ou familial no significado equivocado de apenas referência ou defesa da família.

Abstract: Whereas defining generation has been in the minds of sociologists since the early moments of the discipline, its use has always been theoretically unstable because of its multiple meanings. Even when elevated to a higher theoretical level with Mannheim, it suffered the initial reluctance of certain academic circles in accepting that author's theoretical contributions. Today, generation remains polysemic. And the scarce attention paid to (or perhaps the lack of perception of) generational social positions and to the dynamic of relations between generations is such that it has generated certain analytical shortcomings? as in the case of violence against the aged here treated in which an analysis from the perspective of solidarity and conflict between generations is crucial.

Key words: generations, old age, gender, generational relations, violence. 


\section{Referências}

Adorno, Sérgio \& CARDia, Nancy (1999). "Dilemas do controle democrático da violência; execuções sumárias e grupos de extermínio", in José Vicente Tavares dos Santos (org), Violência em tempo de globalização, São Paulo: Hucitec, pp. 66-90.

A TARDE (2007a). "Anciã de 86 anos era agredida e presa pelo neto", Salvador, março.

— (2007b). "Jovem detido por maus-tratos a idosa", Salvador, julho.

— (2006). "Idosa de 73 anos apanhava do neto", Salvador, novembro.

Attias-Donfut, Claudine (1988). Sociologie des générations, Paris: PUF.

- (1991). "Dynamique socio-historique du cours de vie", in idem, Générations et âges de la vie, Paris: PUF.

— (1993). "Un jeu entre générations", Informations Sociales, n. 30.

— (1995). "Le double circuit des transmissions", in idem (org), Les solidarités entre générations, Paris: Nathan, pp. 41-81.

Balandier, Georges (1977). Antropológicas, São Paulo: Cultrix.

BENGTSON, Vern (1993). "Is the contract across generations changing?", in Vern Bengtson \& Andrew W. Achenbaum (eds), The changing contract across generation, Nova York: Aldine de Gruyter, pp. 3-23.

- (1995). "Effets à long terme du lien filial", in Claudine Attias-Donfut (org), Les solidarités entre générations, Paris: Nathan.

Bernardo, Kátia Jane Chaves (2006); "Novos laços familiares: O fenômeno da coabitação de gerações e a violência contra a pessoa idosa", in Seminário Internacional Fazendo Gênero 7, Florianópolis, UFSC, Anais.

Bourdieu, Pierre (1983). "A 'Juventude' é apenas uma palavra”, in idem, Questões de sociologia, Rio de Janeiro: Marco Zero, pp. 112-121. 
— (1990). Coisas ditas, São Paulo: Brasiliense.

BRItTo da Motta, Alda (1998). "Chegando pra idade”, in Myriam Lins de Barros (org), Velhice ou terceira idade?, Rio de Janeiro: Fundação Getúlio Vargas, pp. 223-235.

(1999). "As dimensões de gênero e classe social na análise do enveIhecimento", Cadernos Pagu, n. 13, "Dossiê Gênero em Gerações", Campinas: Unicamp, pp. 191-221.

— (2002). "Gênero e geração: De articulação fundante a 'mistura indigesta'", in Sílvia Lúcia Ferreira \& Enilda Rosendo Nascimento (orgs), Imagens da mulher na cultura contemporânea, Salvador: Neim/UFBA, pp. 35-49.

- (2003). "Espaço doméstico e gerações: Disputas veladas e renúncias ambíguas", CD, trabalho apresentado ao XI Encontro de Ciências Sociais Norte e Nordeste, Aracaju: Universidade Federal de Sergipe, agosto.

Camarano, Ana Amélia et alii (2004). "Famílias: Espaço de compartilhamento de recursos e vulnerabilidades", in idem (org), Os novos idosos brasileiros: Muito além dos 60?, Rio De Janeiro: Ipea, pp. 137-167.

Delegacia Especial de Atendimento ao Idoso (Deatı) (2006-2008). BOs, Salvador.

Debert, Guita Grin (2001). "A família e as novas políticas sociais no contexto brasileiro", Interseções - Revista de Estudos Interdisciplinares, Ano 3, n. 2, Rio de Janeiro, pp. 71-92.

Debert, Guita Grin \& Gregori, Maria Filomena (2008). “Novas propostas, velhos dilemas", Revista Brasileira de Ciências Sociais, Vol. 23, n. 66, pp. 165-185.

Delbes, Christiane \& Gaymu, Joelle (1993). "Les familles à quatre générations", Informations Sociales, Vol. 32, pp. 8-12.

EISENSTADT, Samuel (1976). De geração a geração, São Paulo: Perspectiva [1956].

Faleiros, Vicente de Paula (2009). "Violência contra a pessoa idosa no Brasil", in Fausto Rodrigues Lima \& Claudiene Santos (orgs), Violência doméstica (vulnerabilidade e desafios na intervenção criminal e multidisciplinar), Rio de Janeiro: Lúmen Júris, pp. 231-242. 
- (2007). Violência contra a pessoa idosa - Ocorrências, vítimas e agressores, Brasília: Universa.

ForACCHI, Marialice M. (1972). A juventude na sociedade moderna, São Paulo: Pioneira.

Fortes, Meyer (1984). "Age, generation and social structure", in David I. Kertzer \& Jennie Keith (orgs), Age and anthropological theory, Nova York: Cornell University, pp. 99-122.

GARRIDO, Edleusa Nery (2004). “Mulheres em situação de violência doméstica: O que faz a Equipe de Saúde da Família?", dissertação de mestrado, Universidade Federal da Bahia.

GodARD, Francis (1993). "Le conflit de générations", Informations Sociales, n. 30, pp. 86-92.

Grun, Roberto (1999). "Conflitos de geração e competição no mundo do trabalho", Cadernos Pagu, n. 13, pp. 63-107.

Guilhon Albuquerque, José Augusto (1977). Movimento estudantil e consciência social na América Latina, Rio de Janeiro: Paz e Terra.

IANNI, Octávio (1963). "O 'jovem radical'”, in idem, Industrialização e desenvolvimento social no Brasil, Rio de Janeiro: Civilização Brasileira.

LenoIR, Remi (1998). "Objeto sociológico e problema social”, in Patrick Champagne, Remi Lenoir \& Dominique Merllié, Iniciação à prática sociológica, Petrópolis: Vozes.

Machado Pals, José \& Blass, Leila Maria (orgs) (2004). Tribos urbanas: Produção artística e identidades, Lisboa: Imprensa de Ciências Sociais/Instituto de Ciências Sociais da Universidade de Lisboa.

Maffesol, Michel (1987). O tempo das tribus, Rio de Janeiro: Forense Universitária.

Mannheim, Karl (s/d). "O problema das gerações" [tradução: Maria da Graça Barbedo], in idem, Sociologia do conhecimento, Vol. II, Porto, RES-Editora, pp. 115-176, [1928]. 
- (1961). Diagnóstico do nosso tempo, Rio de Janeiro: Zahar.

Mauger, Gérard (1990). "Introduction", in Karl Mannheim, Le problème des générations, Paris: Nathan.

— (1990). "Posface", in Karl Mannheim, Le problème des générations, Paris: Nathan.

Menezes, Maria Rosário (1999). "Da violência revelada à violência silenciada: Um estudo etnográfico sobre a violência doméstica contra o idoso", tese de doutorado, São Paulo: USP.

Mentrée, François (1920). Les générations sociales, Paris: Bossard.

Mınayo, Maria Cecília de Souza (2003). "Violência contra idosos: Relevância para um velho problema", Cadernos de Saúde Pública, Vol. 19, n. 3, pp. 783-791.

Ortega y Gasset, José (1923). "La idea de las generaciones”, in idem, El tema de nuestro tiempo, "Obras Completas", Madri: Revista de Occidente, Vol. III, pp. 145-156.

Rifiotis, Theophilos (1998). "O ciclo vital completado: A dinâmica dos sistemas etários em sociedades negro-africanas", in Myriam Lins de Barros (org), Velhice ou terceira idade?, Rio de Janeiro: Fundação Getúlio Vargas, pp. 85-110.

SAfFIOtI, Heleieth I. B. (1994). "Violência de gênero no Brasil contemporâneo", in Heleieth I. B. Saffioti \& Monica Muñoz-Vargas (orgs), Mulher brasileira é assim, Rio de Janeiro/Brasília: Rosa dos Tempos/Unicef/Nipas, pp. 151-185.

Seeger, Anthony (1980). "Os velhos nas sociedades tribais", in idem, Os índios e nós: Estudos sobre sociedades tribais brasileiras, Rio de Janeiro: Campus, pp. 61-79.

Woodward, Kathleen (1995). "Tribute to the older woman: Psychoanalysis, feminism and ageism", in Mike Featherstone \& Andrew Werrick (eds), Images of aging, London: Routledge, pp. 79-96. 